\title{
Hemitórax hiperlúcido unilateral: diagnóstico por imágenes
}

\author{
JOSÉ D. ARCE V.*
}

Unilateral hyperlucent hemithorax in children

Different causes leading to an hyperlucent hemithorax in radiographs are revised, complementing the study with computed tomography for further precision. Pathological characteristics and their images are analyzed.

Key words: Thoracic radiograph, computed tomography, hyperlucid hemithorax.

\section{Resumen}

Se revisan las diferentes causas que pueden determinar un torax hiperlúcido unilateral en estudio radiológico simple de torax, complementando el estudio con tomografia computarizada para una mejor precisión. Se analizan sus características patológicas y su representación en imágenes.

Palabras clave: Radiografía de tórax, tomografía computarizada de tórax, tórax hiperlucido.

\section{Introducción}

En 1953 Swyer y James publican la observación de un hemitórax hiperlúcido, en el estudio radiológico simple de un niño de 6 años, por una causa diferente a las hasta entonces descritas: hiperinsuflación compensatoria o atrapamiento aéreo, secundario a obstrucción parcial de la vía aérea.

La radiografía $(\mathrm{Rx})$ de tórax mostraba una mayor transparencia del hemitórax derecho y el estudio complementario con angiografía y broncografía aportaron una disminución de la vascularización y una menor representación de la vía aérea periférica. Estos hallazgos fueron refrendados con el examen anatomo-patológico del pulmón resecado, cuyo estudio histopatológico demostró lo que conocemos actualmente como bronquiolitis obliterante post-infecciosa ${ }^{1}$.

Esta observación fue confirmada un año más tarde por Mc Leod, quien agregó que la híperlucidez aumenta durante la espiración.

El estado actual de los estudios de imágenes, nos permite confirmar que en la bronquiolitis obliterante, el compromiso siempre es bilateral y asimétrico, siendo esto último lo que determina, en el estudio radiológico, la mayor transparencia unilateral.
En el transcurso de los años, en estudio radiológico simple han sido descritas otras causas de hemitórax hiperlúcido en el niño, las cuales revisaremos, apoyándonos con tomografía computarizada (TC) para confirmar la causa de éstas.

\section{Semiología radiológica}

La transparencia de un hemitórax está determinada principalmente por la cantidad de aire en el espacio aéreo pulmonar, la cantidad de líquido en su espacio vascular e intersticio central o periférico, la densidad de las partes blandas de la pared torácica y una eventual ocupación de la cavidad pleural por aire o líquido.

En el análisis de una Rx de tórax, partiendo por lo general, interesa la simetría tanto en tamaño como en transparencia. En el entendido que el volumen del contenido aéreo es asimétrico, por un normal mayor tamaño del pulmón derecho.

Descartando factores técnicos, alteración de la pared del tórax y patología de la cavidad pleural, una importante cantidad de patología pulmonar congénita o adquirida puede determinar anomalías de transparencia, tanto por atrapamiento aéreo, como causa primaria, o disminución de la vascularización.

* Servicio de Radiología e Imágenes. Clínica Santa María. 
El principal punto a resolver es determinar cuál es el hemitórax afectado. Debe tenerse en cuenta que ocurrido un atrapamiento de aire en el pulmón, independiente de la causa, se produce hipoxia en el parénquima pulmonar periférico e hipercapnia, lo cual lleva a vasoconstricción, que aun cuando no es inmediata es el resultado final. De esta forma, en una asimetría de transparencia el lado anormal será siempre el que presenta una hipovascularización.

Establecida la asimetría debe analizarse si el compromiso del hemitórax afectado es total o localizado, para orientar el manejo y un posible mecanismo causal ${ }^{3,4}$.

\section{Hemitórax hiperlúcido: causas}

Las causas pueden ser diversas y afectar desde la vía aérea principal hasta la pared torácica. $\mathrm{Su}$ significado clínico es variable y algunas de ellas pueden significar una emergencia que precise una rápida respuesta terapéutica. Desarrollaremos las más frecuentes, excluyendo la patología del espacio pleural. Algunas publicaciones recientes hacen una agrupación diferente pero dentro del contexto, de considerar el espacio anatómico comprometido ${ }^{2,3}$.

1. Anomalía de la vía aérea periférica o parénquima pulmonar

a. Bronquiolitis constrictiva post-infecciosa o post-trasplante.

b. Malformación congénita de la vía aérea Tipo IV.

c. Lobectomía.

d. Atresia bronquial.

e. Atelectasia.

f. Otras.

2. Anomalía de la vía aérea principal

a. Híperinsuflación lobar congénita (Enfisema lobar congénito).

b. Compresión extrínseca parcial de la vía aérea.

c. Obstrucción intrínseca parcial de la vía aérea.

3. Anomalía del parénquima pulmonar y circulación pulmonar

a. Pulmón hipoplásico/Agenesia-Aplasia lobar.

b. Atresia de arteria pulmonar/Embolia Pulmonar/Vasoconstricción.

4. Anomalía de la pared torácica

a. Síndrome de Poland

5. Artefactos
Anomalía de la vía aérea periférica o parénquima pulmonar

\section{a. Bronquiolitis constrictiva}

El compromiso de la vía aérea periférica, con inflamación de las paredes del bronquiolo, necrosis epitelial y desarrollo posterior de fibrosis de las paredes bronquiolares, produce una obstrucción parcial con retención de aire durante la espiración ${ }^{4}$.

Las causas pueden ser de origen infeccioso, particularmente por adenovirus tipo 7, aun cuando se ha reportado Mycoplasma, Bordetella pertussis, sarampión y tuberculosis como otros posibles agentes etiológicos. También una reacción injerto-huésped, en pacientes trasplantados de pulmón y médula ósea, puede producir el mismo proceso.

En los casos secundarios a adenovirus nuestra experiencia en una revisión de 23 casos con tomografía computarizada nos indica que siempre el compromiso es bilateral y asimétrico y que la atelectasia cicatrizal, engrosamiento peribronquial y bronquiectasias son hallazgos comunes ${ }^{5}$.

En estudio radiológico simple de tórax, la asimetría del compromiso puede determinar un pulmón hiperlúcido y disminuido de volumen, con una disminución en número y calibre de los vasos (Figura 1). Pero como además la asimetría ocurre entre diferentes sectores de un mismo pulmón, observaremos en TC un mosaico de atenuación, con alternancia de pulmón normal con segmentos comprometidos. Este último hallazgo se hace más evidente en espiración (Figura 2).

\section{b. Malformación congénita de la vía aérea Tipo IV}

Stoker en 1973 realizó una primera clasificación en tres tipos, de la malformación hamartomatosa por detención del desarrollo de la vía aérea fetal, de acuerdo al tamaño de los quistes. Posteriormente, agregó el tipo 0 que ocurre muy precozmente en el desarrollo de la vía aérea y que es también conocido como displasia acinar, incompatible con la vida. El otro tipo agregado es la forma IV que consiste en grandes quistes periféricos, formados por alteración del desarrollo del sáculo alveolar. Este tipo en imágenes es similar al blastoma pulmonar ${ }^{6}$.

La malformación congénita de la vía aérea es la anomalía de desarrollo pulmonar más frecuente y compromete sólo un lóbulo en el 95\% de los casos, sin predilección por alguno en particular. Hay un tejido broncopulmonar displásico distal al segmento afectado. Se plantea como causa una posible atresia o alteración de la segmentación. 

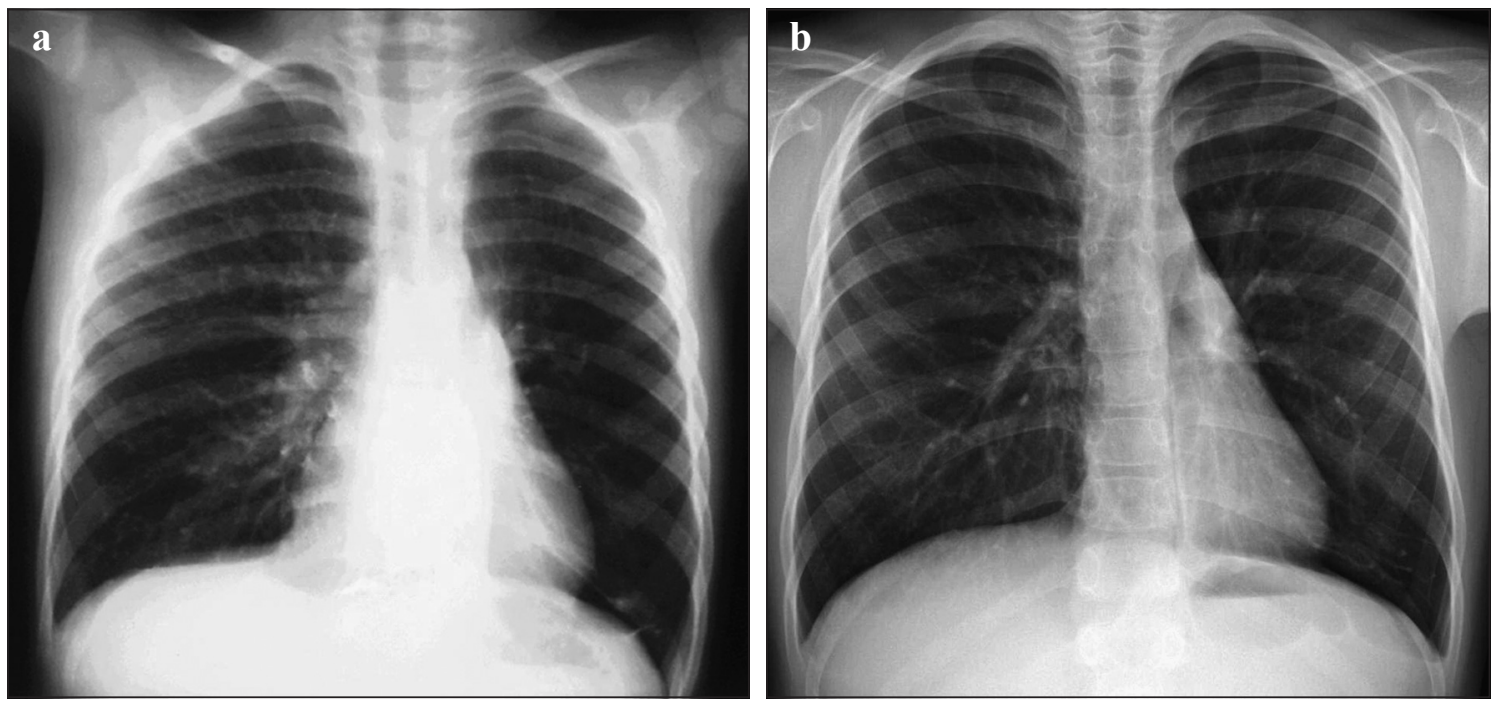

Figura 1 a, b. Bronquiolitis obliterante; a) Niño de 2 años 6 meses; b) Otro paciente de 9 años 11 meses. En ambos casos se observa una mayor transparencia del hemitórax izquierdo con disminución de volumen y una menor cantidad de vasos por área. El hilio izquierdo, en ambos casos, está en posición más baja por una mayor disminución en el volumen del lóbulo inferior.
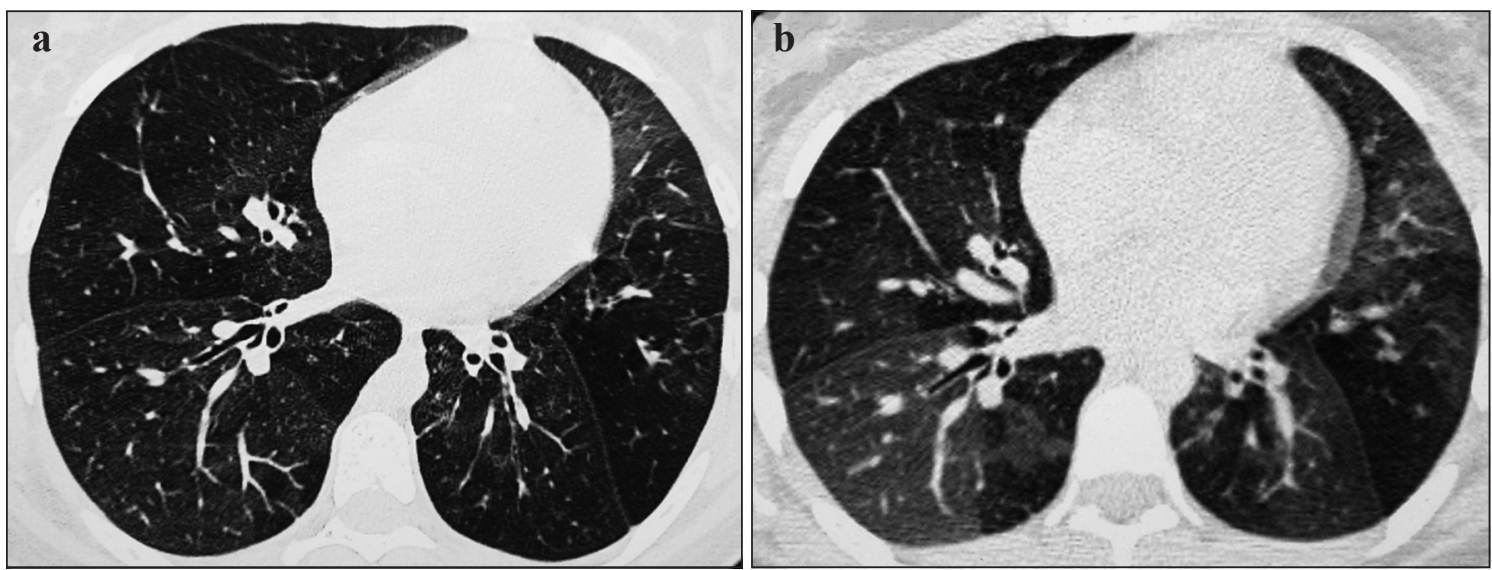

Figura 2 a, b. TC de una niña de 12 años con bronquiolitris constrictiva, secundaria a infección por adenovirus. Mosaico de atenuación; a) Inspiración; b) Espiración. Nótese el compromiso bilateral que afecta partes del pulmón. Las áreas de mayor transparencia corresponden a atrapamiento aéreo y las más densas a pulmón normal.

Puede diagnosticarse en período de recién nacido o en forma tardía, en relación a cuadros infecciosos.

La malformación tipo IV, no siendo la más común, determina en Rx de tórax, por el tamaño de los quistes, una mayor transparencia hacia las zonas periféricas del pulmón que pueden a veces simular un neumotórax. Estos también pueden producir desviación contralateral del mediastino. La TC demuestra claramente las estructuras quísticas (Figura 3).

\section{c. Lobectomía}

La extirpación de una parte del pulmón precisa que los órganos y tejidos remanentes se reorien- ten y expandan en forma compensatoria. De esta forma se produce una disminución de volumen e híperlucidez del hemitórax afectado. En ausencia de antecedentes clínicos, la observación en Rx de tórax, de cambios postquirúrgicos en la parrilla costal, orienta a una correcta interpretación de los hallazgos, aun cuando se debe tener en cuenta que estos pueden estar ausentes en casos de cirugía por videotoracoscopia asistida (Figura 4).

\section{d. Atresia bronquial}

Es una obstrucción congénita localizada de la vía aérea que ocurre a nivel subsegmentario, segmentario o lobar. Afecta generalmente el segmento apicoposterior del lóbulo superior aun 

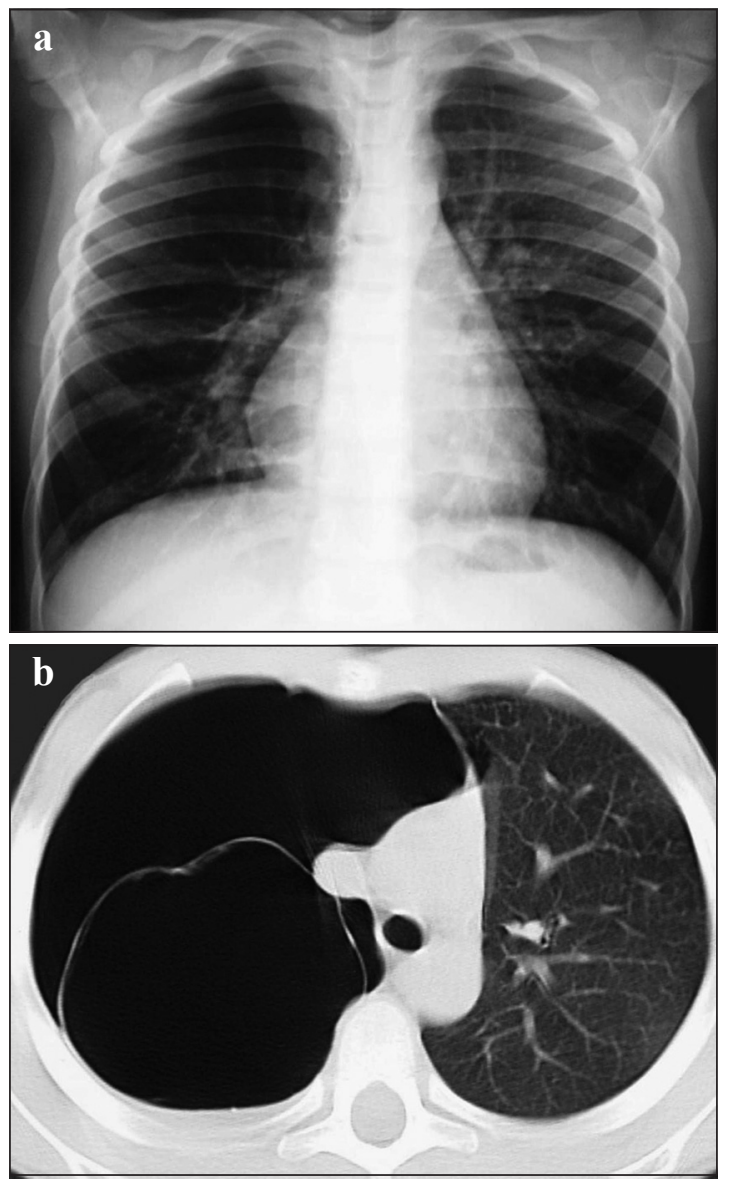

Figura 3 a, b. Malformación de la vía aérea periférica tipo IV, en un niño de 6 años 8 meses. Rx (a) y TC de tórax (b). Hay una mayor transparencia del pulmón derecho, hacia su lóbulo superior, en relación a grandes quistes periféricos que caracterizan esta anomalía.

cuando cualquier parte del pulmón puede ser afectado $^{6}$ (Figura 5).

La gran mayoría de las veces es descubierta en forma incidental.

En el estudio radiológico se observa una estructura tubular con algunas ramificaciones en la parte central, en correspondencia a contenido mucoso atrapado en el bronquio ocluido. En la periferia del segmento de pulmón afectado hay una híperlucidez por flujo de aire colateral y una relativa disminución de la vascularización. Al no existir un mecanismo valvular no se produce atrapamiento aéreo.

\section{e. Atelectasia}

La atelectasia al igual que la lobectomía determina una zona de disminución de volumen que necesita ser compensada por el pulmón remanente. El conocimiento de los diferentes patrones radiográficos de atelectasia ayuda al diagnóstico.

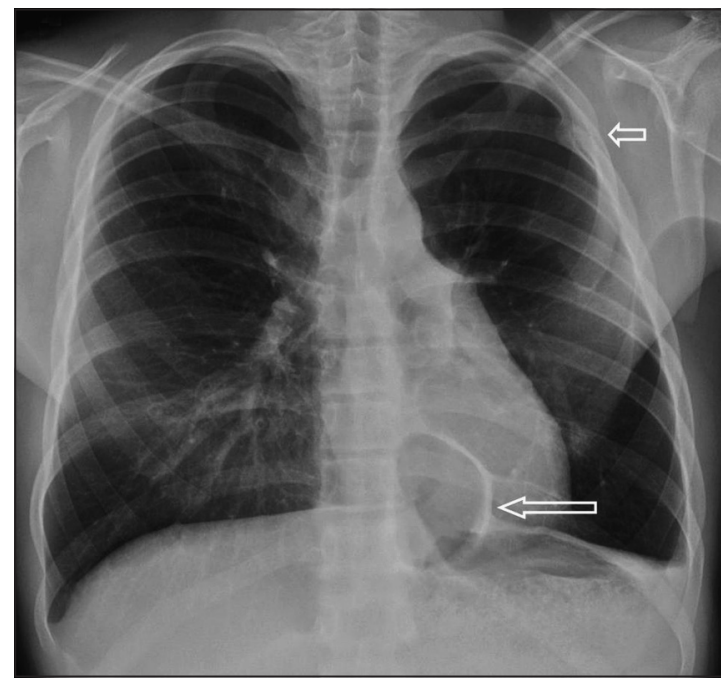

Figura 4. Paciente de 13 años con lobectomía superior izquierda, en el período de lactante, por malformación congénita de la vía aérea. Obsérvese la secuela de antigua toracotomía (flecha corta), en la parrilla costal superior izquierda. La formación retrocardíaca corresponde a una hernia hiatal (flecha larga).
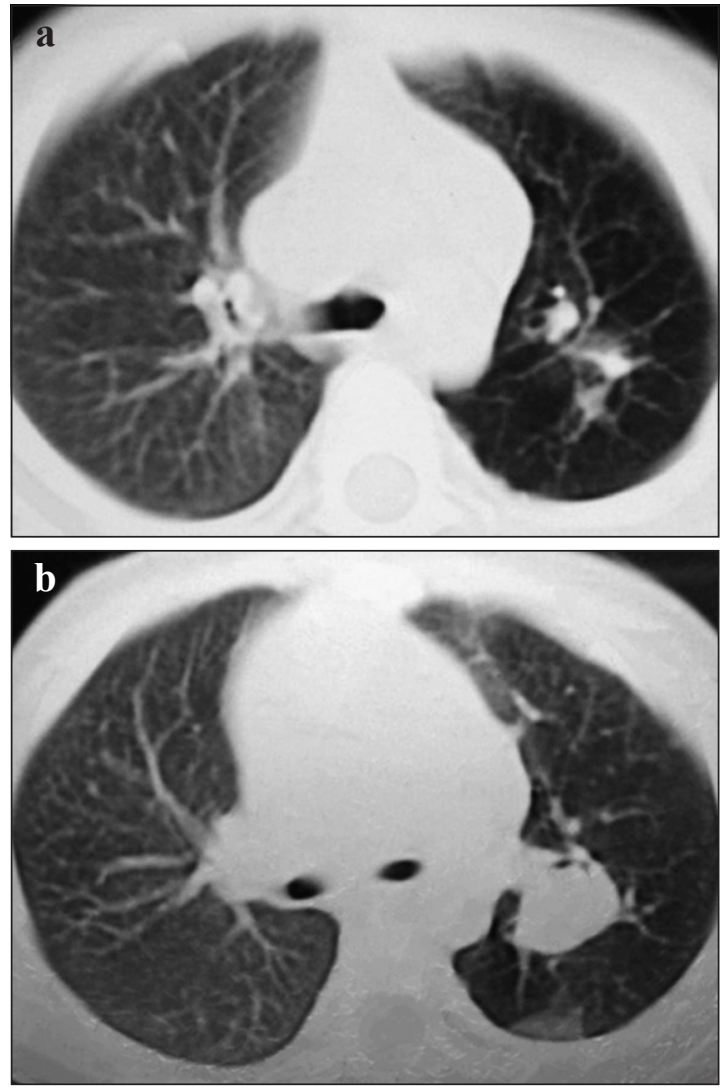

Figura 5 a, b. Atresia bronquial. Cortes en diferentes niveles de TC, que demuestran una zona central densa con prolongaciones digitiformes, correspondientes a mucus en el árbol bronquial obstruido. En la periferia de este se reconoce una zona de mayor transparencia (Gentileza Dra. María E. Ucar). 


\section{f. Otras}

La pérdida de aire al espacio extraalveolar puede producir enfisema intersticial y afectar más a un lado, produciendo hiperlucidez. El daño secuelar a una displasia broncopulmonar puede determinar zonas con falla de alveorización y grandes espacio aéreos que determinen idéntico hallazgo.

Aun cuando poco frecuentes en la actualidad, debe considerarse también como causa de hiperlucidez, al neumatocele post-infeccioso, generalmente causado por estafilococo. Otra causa de neumatocele puede ser el trauma toráxico.

\section{Anomalía de la vía aérea principal}

\section{a. Hiperinsuflación lobar congénita}

Se prefiere actualmente esta denominación a la clásica de enfisema lobar congénito ya que refleja de mejor forma su fisiopatología.

Consiste en una hiperinsuflación progresiva de un lóbulo pulmonar, determinada por atrapamiento aéreo secundario a obstrucción bronquial parcial intrínseca o extrínseca. Las causas son variadas y comprenden malacia, estenosis, pliegues mucosos y engrosamiento bronquial, septos cartilaginosos, incluyendo algunos la atresia bronquial. Todas ellas y cualquier otra no precisada a veces por la cirugía, producen un mecanismo valvular con retención de aire durante la fase espiratoria ${ }^{6}$.

Puede ser congénito o adquirido y muchas veces presentar una resolución espontánea. La mayoría son asintomáticos hasta los 6 meses, pero a veces pueden producir una grave dificultad respiratoria en el período neonatal.
El lóbulo superior izquierdo es el más afectado (42\%); seguido de lóbulo medio (35\%) y lóbulo superior derecho (21\%). Los lóbulos inferiores están comprometidos en menos del $1 \%$ de los casos y compromete más a hombres en una relación 3:1.

El compromiso multilobar o bilateral es raro, siendo menor al $1 \%$ de los casos.

Se presenta principalmente en la forma clásica habiendo sido descrita además una forma polialveolar?.

El estudio radiológico demuestra una hiperinsuflación localizada, desplazamiento contralateral del mediastino, desplazamiento posterior del corazón y compresión del parénquima pulmonar ipsilateral adyacente (Figura 6).

En el período neonatal, el segmento de pulmón comprometido puede retener líquido (Figura 7).

Una causa también a considerar para una hiperinsuflación unilateral con colapso parcial o total del pulmón contralateral es la monointubación.

\section{b. Compresión extrínseca parcial de la vía aérea}

Se relaciona especialmente con anomalías del mediastino. Puede observarse en malformaciones del intestino anterior, tales como quistes broncogénicos, de duplicación esofágica o neurénteri$\cos ^{6}$. Otras causas pueden ser linfadenopatías, tumores o compresión por estructuras vasculares ${ }^{2,3}$.

La más común en niños es el quiste broncogénico, lesión congénita derivada de un brote anómalo del intestino anterior primitivo ventral. Comprende un 40 a $50 \%$ del total de quistes intratorácicos, ubicándose un tercio en pulmón $\mathrm{y}$ dos tercios en mediastino. Estos últimos, en
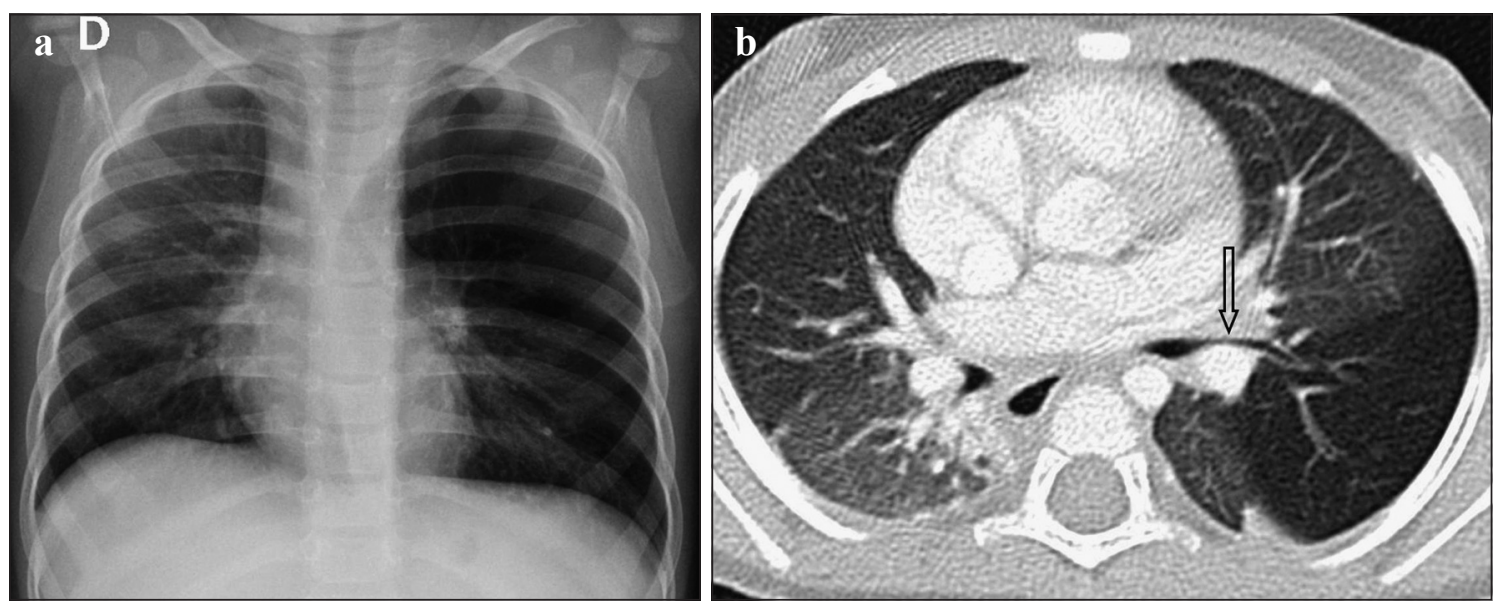

Figura 6 a, b. Híperinsuflación lobar congénita en una niña de 1 año 2 meses en quien se detectó la anomalía en estudio radiológico previo a los 8 meses; a). Rx simple de tórax actual, en la cual se observa una mayor transparencia y volumen en lóbulo superior izquierdo. Hay además disminución de la vascularización y desplazamiento de la línea de unión anterior a derecha; b) TC que demuestra el área hiperinsuflada y una disminución de calibre del bronquio lobar (flecha). 

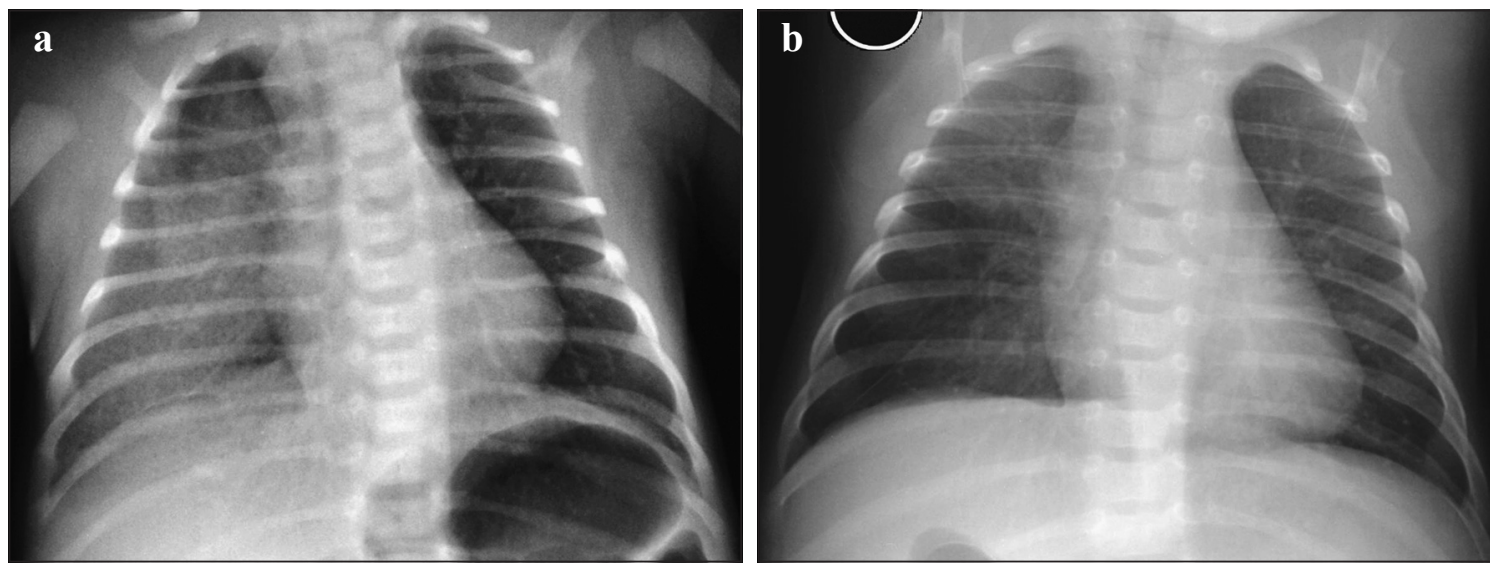

Figura 7 a, b. Hiperinsuflación lobar congénita. Retención de líquido en lóbulo medio en período neonatal y posterior reemplazo por área hiperinsuflada; a) Rx de tórax el primer día de vida; b) Control a los 2 meses.

posición subcarinal pueden producir compresión de un bronquio fuente con obstrucción parcial y atrapamiento aéreo. Otras ubicaciones son hiliar y paratraqueal derecho. Los intrapulmonares son más frecuentes a derecha. Estos quistes raramente se pueden identificar en la raíz del cuello, pericardio o cavidad abdominal ${ }^{6}$.

Sus paredes están recubiertas por epitelio columnar ciliado o cuboideo; contienen músculo liso y a veces cartílago.

Cuando producen obstrucción parcial y están en posición subcarinal además de la hiperlucidez que compromete todo un pulmón, pueden dar algunas alteraciones en las interfases mediastínicas. La TC demostrará su naturaleza quística, extensión y relación con las estructuras vecinas (Figura 8).
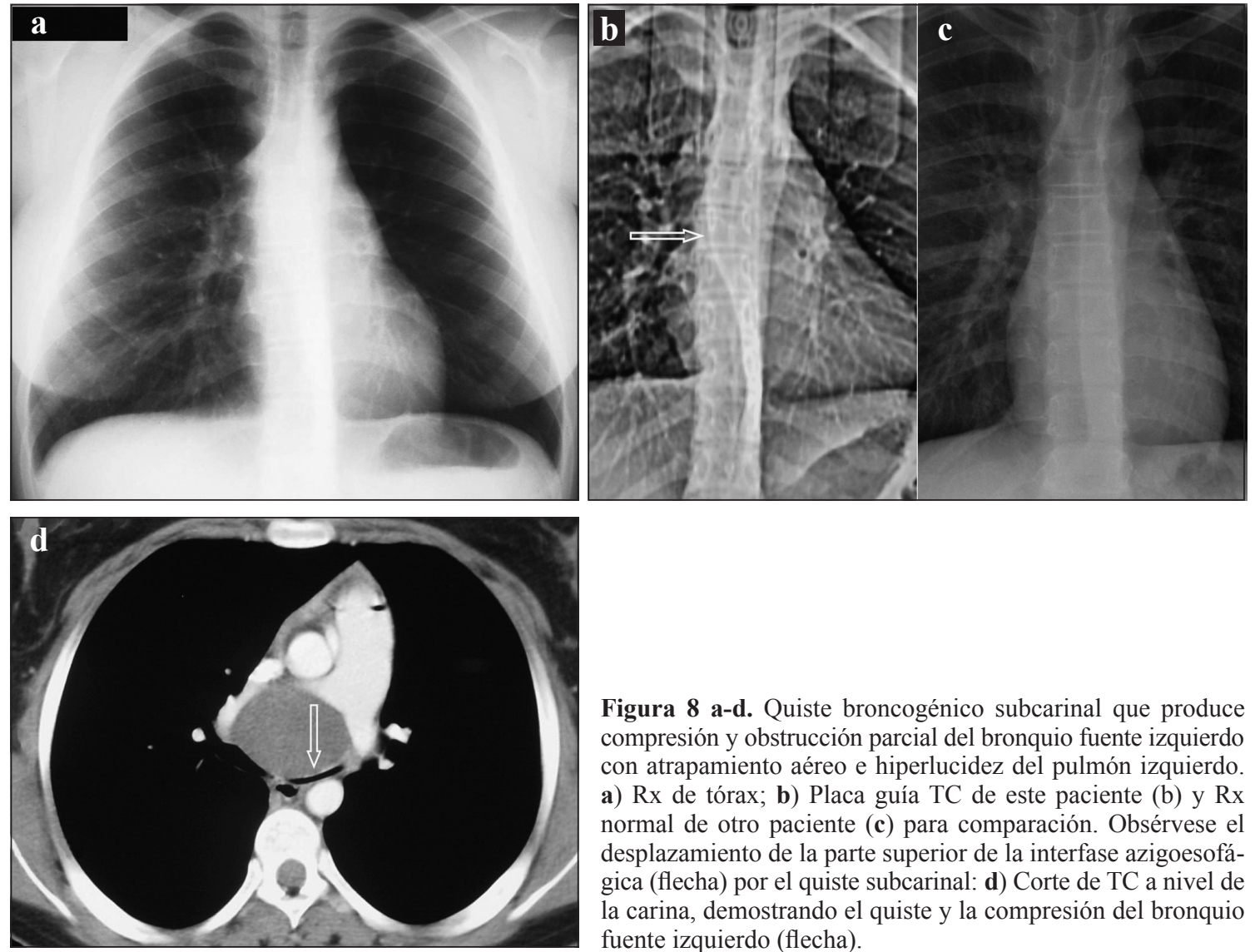

Figura 8 a-d. Quiste broncogénico subcarinal que produce compresión y obstrucción parcial del bronquio fuente izquierdo con atrapamiento aéreo e hiperlucidez del pulmón izquierdo. a) $\mathrm{Rx}$ de tórax; b) Placa guía TC de este paciente (b) y $\mathrm{Rx}$ normal de otro paciente (c) para comparación. Obsérvese el desplazamiento de la parte superior de la interfase azigoesofágica (flecha) por el quiste subcarinal: d) Corte de TC a nivel de la carina, demostrando el quiste y la compresión del bronquio fuente izquierdo (flecha). 
Otras causas de obstrucción extrínseca constituyen las estructuras vasculares tales como colaterales arteriales aortopulmonares, arterias pulmonares anómalas incluida la cuerda pulmonar entre otras. Dependiendo del grado de obstrucción, estas estructuras producirán hiperinsuflación o atelectasia.

\section{b. Obstrucción intrínseca parcial de la vía aérea}

En niños generalmente se produce por cuerpos extraños, siendo rara por tumores endobronquia$\operatorname{les}^{2,3}$.

Los tumores endobronquiales en niños son raros, siendo el más común el carcinoide endobronquial; además pueden observarse el tumor mucoepidermoide y el miofibroblástico o pseudotumor inflamatorio ${ }^{8}$.

Los cuerpos extraños son más frecuentes entre los 6 meses y 3 años, la mayoría de ellos de baja densidad radiológica, generalmente vegetales ${ }^{9}$.

Habitualmente existe un alto índice de sospecha clínica, aun cuando en ocasiones el diagnóstico es tardío. Algunos estudios han demostrado que entre 24 y $34 \%$ tienen Rx de tórax normal, con broncoscopia positiva.

Los hallazgos radiológicos variarán de acuerdo al tamaño, ubicación, tiempo y naturaleza del material aspirado. Frecuentemente producen obstrucción parcial con atrapamiento aéreo distal al segmento de vía aérea afectada, menos común es la obstrucción total con atelectasia del pulmón distal. En ocasiones son radio-opacos facilitando su diagnóstico.

En la obstrucción parcial el estudio radiológico demostrará una mayor transparencia de un lóbulo o pulmón en relación a la ubicación del cuerpo extraño, con disminución de la vascularización (Figura 9).

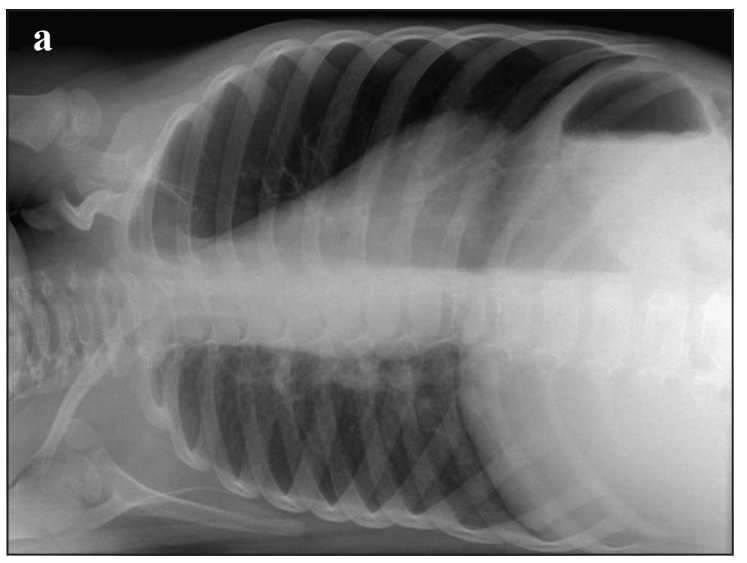

La hiperinsuflación pulmonar, a veces difícil de demostrar en niños pequeños, puede ser mejor objetivada en placas en decúbito lateral con rayo horizontal o estudio radioscópico (Figura 10). Este último demostrará movimiento anormal del mediastino hacia el lado normal durante la espiración efecto conocido como bandeo mediastinico. En niños que colaboran una serie inspiración- espiración objetiva mejor los hallazgos.

\section{Anomalía del parénquima pulmonar y circulación pulmonar}

\section{a. Pulmón hipoplásico/Agenesia-Aplasia lobar}

La hipoplasia ocurre por un desarrollo deficiente o incompleto del pulmón, con un menor número y tamaño de vasos, bronquios y alvéolos. Está directamente influenciada por factores que comprometen el espacio disponible para el creci-

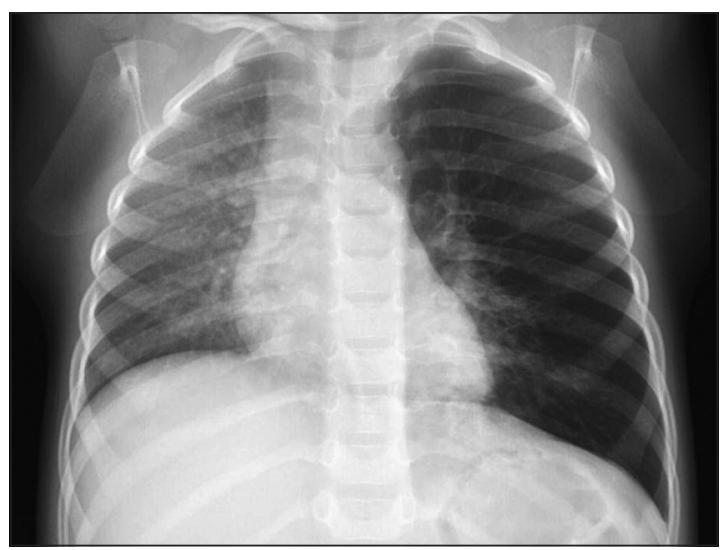

Figura 9. Cuerpo extraño en bronquio fuente izquierdo (maní) en un niño de 2 años 6 meses. Obsérvese la hiperinsuflación, aumento de transparencia y disminución de vascularización que compromete todo el pulmón izquierdo.

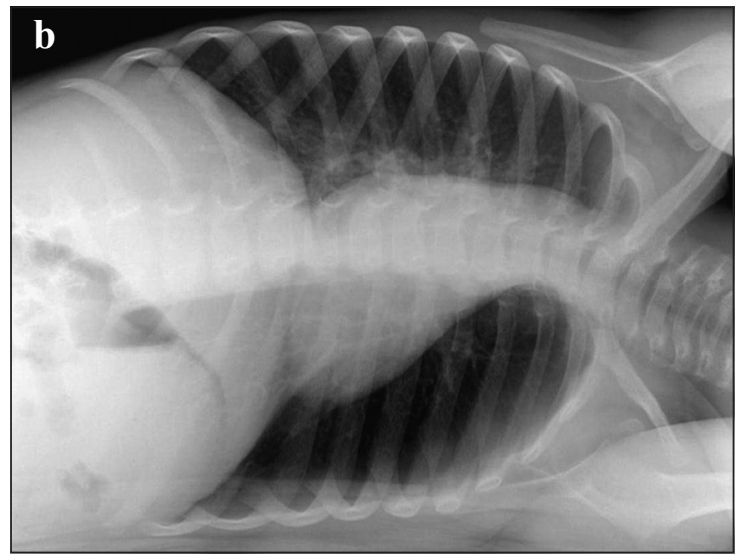

Figura 10 a, b. Radiografías en decúbito lateral derecho (a) e izquierdo (b) demostrando retención de aire a izquierda por cuerpo extraño en bronquio fuente. Se demuestra retención de aire por hiperlucidez mantenida en el decúbito lateral izquierdo (b). 

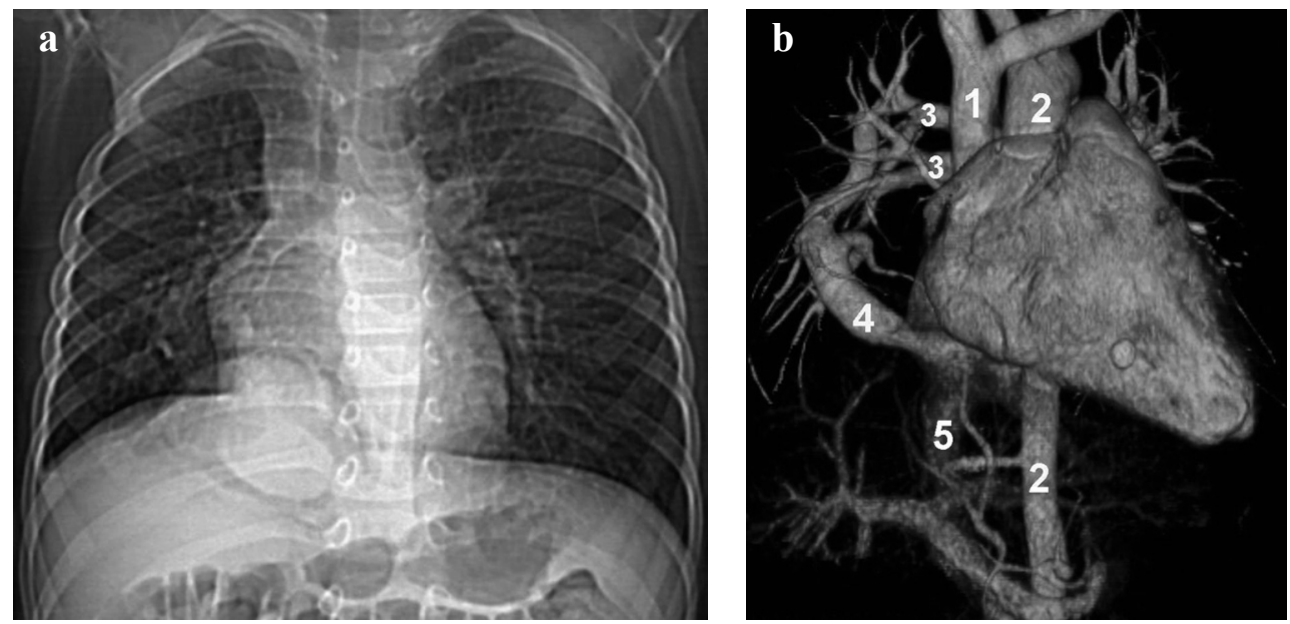

Figura 11 a, b. Aplasia lobar derecha con drenaje venoso pulmonar anómalo a vena cava inferior (cimitarra); a) Placa guía de TC demostrando una disminución de volumen del hemitórax derecho, una eventración diafragmática de este lado y una estructura tubular en la base de este lado; b) Reconstrucción 3D de TC con contraste, en fase vascular. 1: Vena cava superior 2: Aorta 3: Arterias pulmonares 4: Tronco venoso pulmonar derecho drenando en vena cava inferior (cimitarra) 5: Vena cava inferior.

miento pulmonar, siendo la hernia diafragmática la causa más frecuente ${ }^{6}$. El grado dependerá del volumen y duración de la causa.

Complicaciones de esta patología pueden ser neumotórax e hipertensión pulmonar.

La agenesia o aplasia puede afectar a todo un pulmón o un lóbulo. En este último caso afecta principalmente al lóbulo superior del hemitórax derecho y se puede asociar a anomalías del retorno venoso. Aun cuando es difícil de demostrar, generalmente hay algún grado de irrigación arterial desde la aorta torácica y alteración de arterias pulmonares.

Una particular forma de aplasia lobar con anomalía del retorno venoso es el drenaje del flujo venoso pulmonar hacia venas sistémicas, generalmente hacia la vena cava inferior. Esta anomalía es llamada "síndrome de la cimitarra", por la forma que adquiere el transcurso de la vena de drenaje (Figura 11).

Las manifestaciones clínicas estarán en relación al flujo derivado y a la existencia de una cardiopatía congénita asociada.

En otros casos, el retorno venoso pulmonar se puede hacer por una vena única en lugar de las dos habituales, pero siempre a la aurícula izquierda, o bien puede haber derivación mixta del flujo hacia venas pulmonares y sistémicas.

\section{b. Atresia o interrupción proximal de la arteria pulmonar}

Rara anomalía congénita relacionada a una alteración del desarrollo del sexto arco aórtico, la cual afecta a la rama pulmonar contralateral al arco aórtico. Hacia la periferia el pulmón puede recibir arterias colaterales. Puede asociarse a cardiopatía congénita.

El pulmón afectado es más pequeño y el contralateral se observará hiperexpandido, con desviación del mediastino y línea de unión anterior. El estudio angiográfico con TC demostrará la ausencia de la rama pulmonar y anomalías asociadas (Figura 12).

\section{Anomalía de la pared torácica}

\section{a. Síndrome de Poland}

Descrito por A. Poland en 1841. Consiste en anomalías en un lado de la pared torácica con o

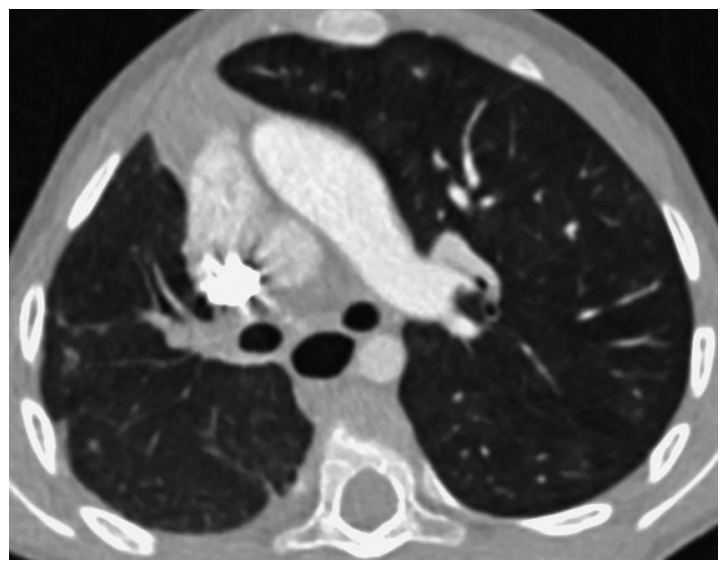

Figura 12. Atresia de arteria pulmonar derecha. Corte axial TC, en fase vascular demostrando el tronco de la pulmonar y su rama izquierda. 


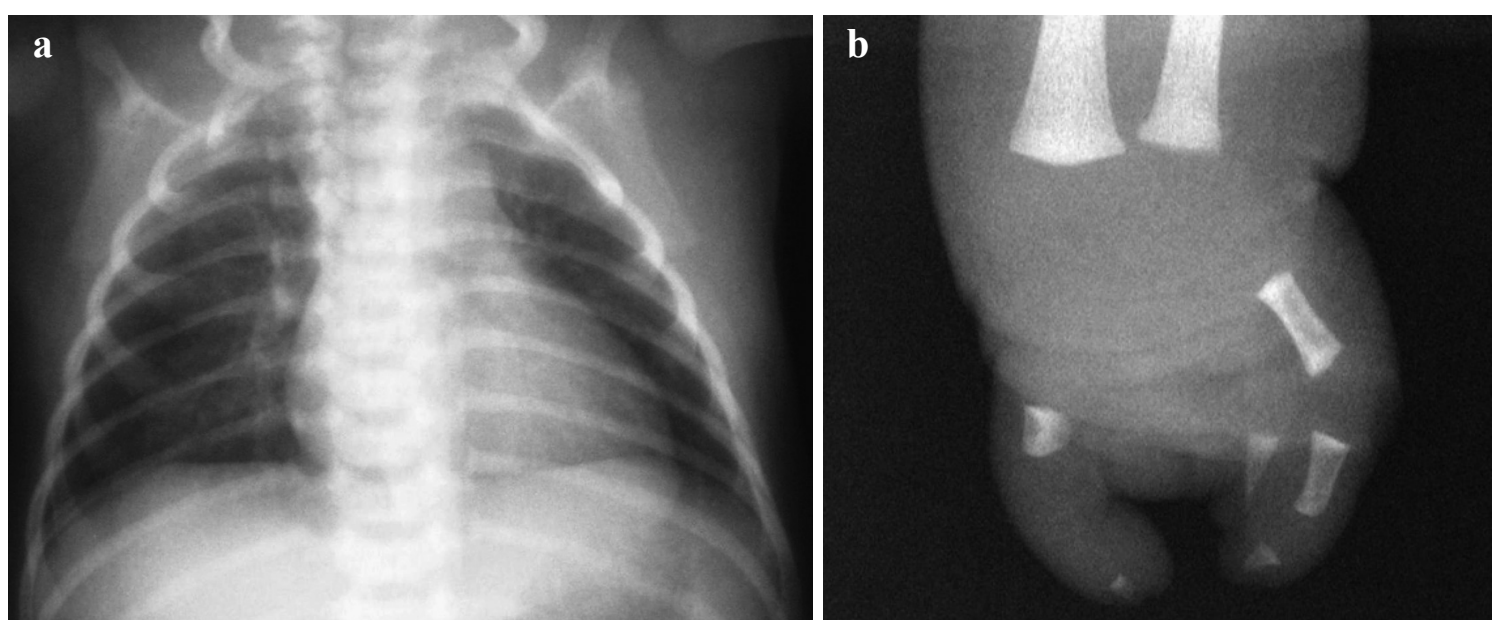

Figura 13 a, b. Síndrome de Poland; a) Rx de tórax demostrando una mayor transparencia del hemitórax derecho y una menor densidad de los tejidos blandos de la pared torácica superior; b) Rx de mano derecha demostrando anomalías esqueléticas relacionadas a la alteración vascular que altera el desarrollo de la pared costal y extremidad superior ipsilateral.

sin compromiso de la extremidad superior ipsilateral.

Su incidencia es de 1 en 30.000, siendo más común a derecha en una proporción $2: 1$ y en hombres, en una relación de 2-3:1.

$\mathrm{Su}$ posible causa sería una alteración circulatoria en la sexta semana fetal ${ }^{11}$.

Hay ausencia de la porción esternal del pectoral mayor y puede haber además hipoplasia o aplasia del pectoral menor, serrato, deltoides, dorsal ancho, hipoplasia o aplasia del tejido mamario o pezón, escaso desarrollo del celular subcutáneo y vello axilar, deformidad de costillas y cartílagos costales entre los segmentos segundo a quinto, braquisindactilia, aplasia o hipoplasia de dedos y dextrocardia cuando la anomalía es izquierda (Figura 13).

\section{Artefactos}

La rotación del paciente, de común ocurrencia en la práctica pediátrica, es la causa más frecuente de pulmón hiperlúcido. Hacia el lado que el paciente rota es donde se produce la hiperlucidez habiendo una absorción asimétrica del haz de rayos simulando un atrapamiento aéreo. La escoliosis puede producir un efecto similar ${ }^{12}$.

Otro artefacto puede producirse por un inadecuado alineamiento del haz de rayos (Figura 14).

\section{Conclusiones}

- Ante una asimetría pulmonar, tanto en tamaño, como en transparencia, la disminución del flujo indica el lado anormal.

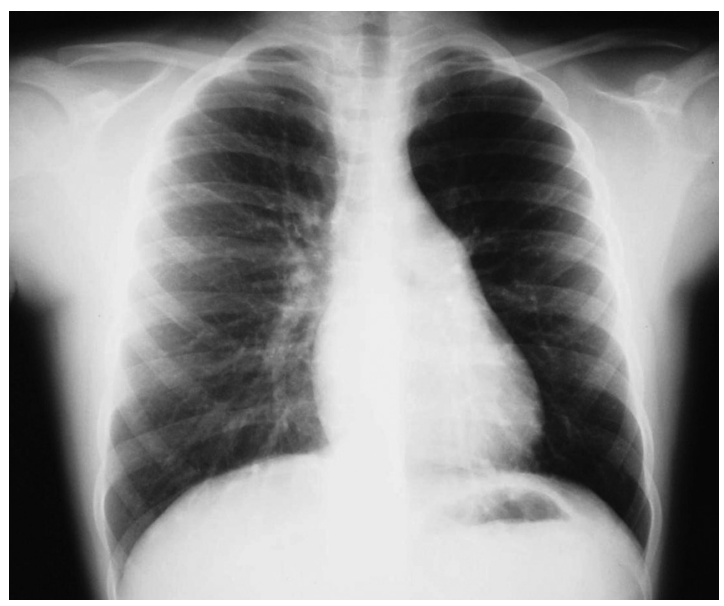

Figura 14. Artefacto derivado de un mal alineamiento del haz de rayos. Hay una mayor transparencia del hemitórax izquierdo y una disminución de la densidad de la totalidad de los tejidos blandos de la pared torácica izquierda.

- Un pulmón hiperlúcido más disminución de flujo, generalmente refleja atrapamiento aéreo.

- Una serie radiográfica inspiración-espiración, puede ayudar a discriminar el lado anormal, en casos de atrapamiento aéreo.

- Los cambios en el flujo pulmonar tardan un tiempo, por tanto, no son evidentes en fases precoces.

- Además de la hipoxia, la compresión de los vasos por el aire atrapado contribuye a la hipovascularización.

- Un pulmón hiperinsuflado rara vez producirá atelectasia del pulmón contralateral. 


\section{Bibliografía}

1.- SWYER P R, JAMES G C W. A case of unilateral pulmonary emphysema. Thorax 1953; 8: 133-6.

2.- DILLMAN J R, SÁNCHEZ R., LADINO-TORRES M F, YARRAM SG, STROUSE P J, LUCAYA J. Expanding upon the Unilateral Hyperlucent Hemithorax in Children. Radiographics 2011; 31: 723-41.

3.- WASILEWSKA E, LEE E Y, EISENBERG R L. Unilateral Hyperlucent Lung in Children. AJR 2012; 198: W400-14.

4.- PIPAVATH S J, LYNCH D A, COOL C, BROWN K K, NEWELL J D. Radiologic and pathologic features of bronchiolitis. AJR 2005; 185: 354-63

5.- ARCE J D, MONDACA R, MARDONES R, VELOZO L, PARRA G. Secuelas post-infección por adenovirus: evaluación por tomografía computada. Rev Chil Radiol 2002; 8: 154-63.

6.- BIYYAM D R, CHAPMAN T, FERGUSON M R, DEUTSCH G, DIGHE M K. Congenital lung abnormalities: Embryologic features, prenatal diagnosis, and postnatal radiologic-pathologic correlation. Radiographics 2010; 30: 1721-38.

7.- MANI H, SUÁREZ E, STOCKER J T. The morphologic spectrum of infantile lobar emphysema: a study of 33 cases. Paediatric Respiratory Reviews 2004; 5 (Suppl A): S313-20.

8.- YIKILMAZ A, LEE E Y. CT imaging of mass-like nonvascular pulmonary lesions in children. Pediatr Radiol 2007; 37: 1253-63

9.- TAHIR N, RAMSDEN W H, STRINGER M D. Tracheobronchial anatomy and the distribution of inhaled foreign bodies in children. Eur J Pediatr 2009; 168: 289-95.

10.- DAVIS S D. Case 28: Proximal interruption of the right pulmonary artery. Radiology 2000; 217: 437-40.

11.- JEUNG M Y, GANGI A, GASSER B, VASILESCU C, MASSARD G, WIHLM J M, et al. Imaging of Chest Wall Disorders. Radiographics 1999; 19: 617-37.

12.- ENRIQUEZ G, GARCÍA-PEÑA P, LUCAYA J. Pitfalls in chest imaging. Pediatr Radiol 2009; 39 (Suppl 3): 356-68.

Correspondencia a:

Dr. José Domingo Arce V.

Servicio de Radiología e Imágenes

Clínica Santa María

E-mail.jarce@csm.cl 